\title{
Neuroprotective effects of arbutin against oxygen and glucose deprivation-induced oxidative stress and neuroinflammation in rat cortical neurons
}

JINGJING TAN ${ }^{1}$

MANOJ KUMAR YADAV 2

SUSHMA DEVI ${ }^{2}$

MANISH KUMAR ${ }^{2,3^{*}}$

${ }^{1}$ Department of Anesthesia and Perioperative Medicine, Shanghai Fourth People's Hospital, Affiliated to Tongji University, Shanghai 200081 China

${ }^{2}$ Department of Pharmacology, Swift School of Pharmacy, Ghaggar Sarai Rajpura (Patiala) Punjab - 140401, India

${ }^{3}$ Chitkara College of Pharmacy, Chitkara University, Rajpura (Patiala) Punjab - 140401, India

\begin{abstract}
In this study, the neuroprotective potential of arbutin (100 $\mu \mathrm{mol} \mathrm{L}{ }^{-1}$ ) pre-treatment and post-treatment against oxygen/ glucose deprivation (OGD) and reoxygenation (R) induced ischemic injury in cultured rat cortical neurons was explored. The OGD $(60 \mathrm{~min})$ and reoxygenation $(24 \mathrm{~h})$ treatment significantly $(p<0.001)$ compromised the antioxidant defence in cultured neurons. Subsequently, an increase $(p<0.001)$ in lipid peroxidation and inflammatory cytokines (tumour necrosis factor- $\alpha$ and nuclear factor kappa-B) declined neuron survival. In pre- and post-condition experiments, treatment with arbutin enhanced both survival $(p<0.01)$ and integrity $(p<0.05)$ of cultured neurons. Results showed that arbutin protects $(p<0.05)$ against peroxidative changes, inflammation, and enhanced the antioxidant activity (e.g., glutathione, superoxide dismutase and catalase) in cultured neurons subjected to OGD/R. It can be inferred that arbutin could protect against ischemic injuries and stroke. The anti-ischemic activity of arbutin can arrest post-stroke damage to the brain.
\end{abstract}

Keywords: arbutin, cerebral ischemia, inflammation, oxidative stress

Oxidative stress and underlying neuroinflammation increase the risk of cerebral ischemia manyfold (1). Reactive oxygen species (ROS) and reactive nitrogen species (RNS) can modify protein structure resulting in vascular remodelling and neuronal injury $(2,3)$. Peroxidation of lipids gives rise to highly reactive aldehydes that form neurotoxic aggregates with biological substrates such as advanced-glycation end products, DNA, and methylglyoxal (3). Free radicals enhance the preponderance of ischemic attack and are also implicated in post-ischemia complications $(4,5)$. Under ischemic conditions, excessive excitatory signals in the brain intensify redox-imbalance and intracellular calcium overload that impedes aerobic respiration and ATP formation. Lack of blood supply creates an ischemic zone populated by pro-inflammatory cytokines, adhesion factors, neutrophils, macrophages, and lymphocytes $(3,4)$. Furthermore, upregulation of transcription activity of

\footnotetext{
*Correspondence; e-mail: mkpharmacology@gmail.com
} 
nuclear factor kappa-B $(\mathrm{NF} \kappa \mathrm{B})$ augments the expression of inflammatory genes and encoding of cytokines and chemokines (6). These sequences of events lead to hemodynamic disturbances that precede an ischemic attack. Within a few hours after ischemia, pro-inflammatory cytokines instigate the expression of chemotactic factors that further aggravate the brain injury (7). Brain autopsy of ischemic patients revealed a pathogenic increase in pro-inflammatory cytokines such as tumour necrosis factor- $\alpha$ (TNF- $\alpha$ ) and chemokines (8). Several lines of evidence indicate that phytoproducts might avert or even modify the pathogenesis of cerebral ischemic injury (2).

Arbutin (4-hydroxyphenyl- $\beta$-D-glucopyranoside) is a natural hydroquinone abundantly present in plants like Origanum majorana (Lamiaceae), Arctostaphylos uva-ursi (Ericaceae), Pyrus communis (Rosaceae) and Bergenia crassifolia (Saxifragaceae) (9). Earlier findings support antihypertensive, antidiabetic, antiseizure, antimicrobial, gastroprotective, hepatoprotective, and antihyperlipidaemic properties of arbutin (10-14). Arbutin inhibits several enzymes (e.g., tyrosinase, $\alpha$-amylase and $\alpha$-glucosidase), free radicals, and downregulates the transcription of many pro-inflammatory cytokines $(10,15)$. Previous studies indicated improvement in motor-functions and behavioural parameters by arbutin that emphasized its neuroprotective action (16-18). Experimental evidence shows that arbutin can alleviate the excitotoxic and autophagic mechanisms of neurodegeneration $(14,17)$. However, there is a need to explore the neuroprotective potential of arbutin to sufficient depth. In the present study, we aimed to establish the anti-ischemia and neuroprotective effects of arbutin using in vitro protocols.

\section{EXPERIMENTAL}

\section{Materials}

Arbutin (purity $>98 \%$ ) was procured from Sigma-Aldrich (USA) and prepared in $0.01 \%$ dimethylsulfoxide (DMSO) (Himedia, India). Dulbecco's Modified Eagle's medium (DMEM), ethylenediaminetetraacetic acid (EDTA), foetal bovine serum (FBS), hydrogen peroxide, 3-(4,5-dimethylthiazole-2-yl)-2,5-dipenyltetrazolium bromide (MTT), nicotinamide adenine dinucleotide (NAD ${ }^{+}$and $\left.\mathrm{NADH}\right)$ and trypsin were from Himedia; 5,5'-dithio-bis-2-nitrobenzoic acid (DTNB), glacial metaphosphoric acid, disodium hydrogen phosphate, manganese chloride $\left(\mathrm{MnCl}_{2}\right)$ and 2-mercaptoethanol were from SRL (India). Thiobarbituric acid (TBA) and trichloroacetic acid (TCA) were procured from Loba Chemie (India).

\section{Animals and primary cortical neurons culture}

Forty Wistar rats (either sex, days $0-1$, weight range 7-9 g) were used in this study. The guidelines provided by the Committee for the Purpose of Control and Supervision of Experiments on Animals (CPCSEA), New Delhi (India), were followed. The research protocol was duly approved by the institutional animal ethics committee (IAEC). The rat pups were euthanized and brains were harvested in a sterile environment. After separation of the meninges, the cortex was isolated and rinsed with sterile phosphate buffer saline (PBS, pH 7.4). The cortical tissue was pulverized into smaller sizes, triturated and digested with $0.25 \%$ trypsin for $20 \mathrm{~min}$ at $37^{\circ} \mathrm{C}$, which was then inactivated by $10 \%$ decomplemented foetal bovine serum (FBS). The mixture was triturated through a pipette to make a homogenous 
preparation, filtered through 70- $\mu \mathrm{m}$ sterilized filters and the filtrate was centrifuged (CPR-30 Remi Compufuge, Vasai, India) for $10 \mathrm{~min}$ at $300 \times g$. The sediment was washed once with PBS and suspended in the plating medium, DMEM, containing $0.225 \%$ sodium bicarbonate, $1 \mathrm{mmol} \mathrm{L}^{-1}$ sodium pyruvate, $2 \mathrm{mmol} \mathrm{L}^{-1}$ L-glutamine, $0.1 \%$ dextrose, $100 \mathrm{U} \mathrm{mL}^{-1}$ penicillin, $0.1 \mathrm{mg} \mathrm{mL} \mathrm{mL}^{-1}$ streptomycin and $5 \%$ FBS. The pellet was washed twice in this medium. Neurons are then plated on poly-L-lysine pre-coated plates or glass coverslips at the density of $2 \times 10^{6} \mathrm{cells} \mathrm{cm}^{-2}$. Neurons are grown in a plating medium consisting of $89 \%$ high-glucose DMEM, $10 \%$ foetal bovine serum, $100 \mathrm{U} \mathrm{mL}^{-1}$ penicillin, $0.1 \mathrm{mg} \mathrm{mL}^{-1}$ of streptomycin. After $24 \mathrm{~h}$, the medium was changed to a fresh neurobasal medium supplemented with $2 \%$ B27 (neuron supplement, Invitrogen, Thermo Fisher Scientific, USA) and $100 \mathrm{U} \mathrm{mL}^{-1}$ penicillin, $0.1 \mathrm{mg} \mathrm{mL}^{-1}$ of streptomycin, and then refreshed every 2-3 days. Cultures were incubated at $37^{\circ} \mathrm{C}$ in a $95 \%$ air $/ 5 \% \mathrm{CO}_{2}$ in a humidified incubator. Experiments were performed at 5-7 days of neuron culture growth in vitro $(19,20)$.

\section{Oxygen-glucose deprivation (OGD) and arbutin treatment}

The culture medium was changed to glucose-free DMEM in order to deprive the rat cortical neurons of $\mathrm{O}_{2}$ and glucose (OGD). The cultured neurons were washed twice with glucose-free DMEM, and thereafter incubated in a hypoxic chamber at $37^{\circ} \mathrm{C}$ for $1 \mathrm{~h}$, equilibrated with $94 \% \mathrm{~N}_{2}, 1 \% \mathrm{O}_{2}$ and $5 \% \mathrm{CO}_{2}$. After completion of 1-h OGD, the medium was

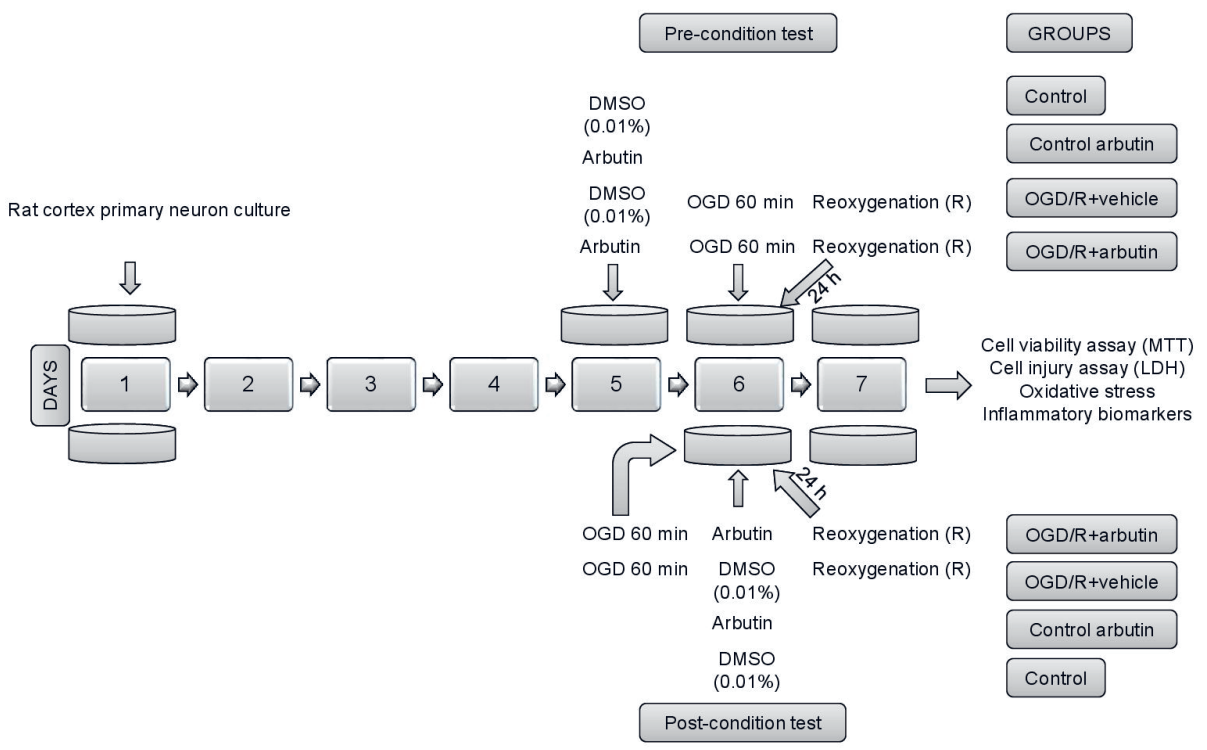

Fig. 1. Experimental protocol used in the present study. In the precondition experiment, cultured rat cortical neurons were pre-treated with the dimethylsulfoxide (DMSO) vehicle or arbutin $\left(100 \mu \mathrm{mol} \mathrm{L}^{-1}\right)$ for $24 \mathrm{~h}$ followed or not by oxygen and glucose deprivation (OGD) and reoxygenation (R). In the postcondition experiment, rat primary neurons were subjected to OGD in a glucose-free medium, and, thereafter, treated with vehicle or arbutin $\left(100 \mu \mathrm{mol} \mathrm{L}^{-1}\right)$ before reoxygenation. 
replaced with neurobasal medium supplemented with $2 \%$ B27 and neurons were incubated for $24 \mathrm{~h}$ under normoxic conditions $\left(95 \%\right.$ air and $5 \% \mathrm{CO}_{2}$ at $37{ }^{\circ} \mathrm{C}$ ). For measurements of MTT and enzyme activity, rat cortical neurons were cultured in a neurobasal medium supplemented with $2 \% \mathrm{~B} 27,100 \mathrm{U} \mathrm{mL}^{-1}$ penicillin and $0.1 \mathrm{mg} \mathrm{mL}^{-1}$ streptomycin $(21,22)$. A total of eight groups ( $n=5$ in each group) were undertaken for pre- and postconditioning experiments (Fig. 1). For control experiments, the neuron cultures were subjected to identical conditions and treated with either $0.01 \%$ DMSO vehicle (control) or arbutin $\left(100 \mu \mathrm{mol} \mathrm{L}{ }^{-1}\right)$ (control arbutin) for $24 \mathrm{~h}$, except $60 \mathrm{~min}$ of OGD and $24 \mathrm{~h}$ of reoxygenation (R) (OGD/R). OGD/R+vehicle group was treated with $0.01 \%$ DMSO for $24 \mathrm{~h}$ before OGD/R (pre-condition experiment) or immediately after OGD before reoxygenation (post-condition experiment). OGD/R+arbutin group was treated with arbutin $\left(100 \mu \mathrm{mol} \mathrm{L}^{-1}\right)$ for $24 \mathrm{~h}$ before OGD/R (pre-condition experiment) or immediately after OGD before reoxygenation (post-condition experiment) (23).

\section{Cell viability assay}

The viability of cells is examined by 3-(4,5-dimethylthiazole-2-yl)-2,5-dipenyltetrazolium bromide (MTT) assay. This test determines the metabolically active mitochondria in the cells. Cells were seeded in 96-well plates at $5 \times 10^{3}$ cells per $100 \mu \mathrm{L}$. After 5 days of growth, cells were subjected to OGD and reoxygenation, with arbutin added into the medium. After $24 \mathrm{~h}$ of reoxygenation, MTT (yellow color salt) was added $(2 \mathrm{~mL})$ to the cells at the final concentration of $0.5 \mathrm{mg} \mathrm{mL}^{-1}$ and the plates were incubated for $24 \mathrm{~h}$ at $37^{\circ} \mathrm{C}$. During incubation, living cells converted (via mitochondrial dehydrogenase) the tetrazolium component of the dye solution into a formazan product (purple color). The insoluble formazan product was then precipitated by centrifugation, the supernatant is removed and $150 \mu \mathrm{L}$ DMSO is added for $20 \mathrm{~min}$ to solubilize the formazan product. Absorbance which is directly proportional to the number of surviving cells is measured on a microplate reader (Bio-Rad, USA) at $570 \mathrm{~nm}(24)$.

\section{Cell injury assay}

Cell injury is detected by measuring lactate dehydrogenase (LDH). The assay is based on the reduction of $\mathrm{NAD}^{+}$by $\mathrm{LDH}$. The resulting $\mathrm{NADH}$ is utilized in the stoichiometric conversion of a tetrazolium dye. $\mathrm{LDH}$ release is measured in the culture medium using the LDH assay kit (Sigma-Aldrich). Culture medium $(100 \mu \mathrm{L})$ is transferred from culture wells to 96-well plates and mixed with the $100 \mu \mathrm{L}$ reaction solution provided in the kit. Absorbance is measured at $490 \mathrm{~nm} 30$ min later using a microplate reader (25). The background absorbance of the multi-well plates measured at $690 \mathrm{~nm}$ is subtracted.

\section{Oxidative stress}

The cultured neurons were harvested, sonicated for $3 \mathrm{~min}$ in an ice-cold water bath, proteins were precipitated with $4.5 \%$ trichloroacetic acid (TCA) and centrifuged (10 min at $3000 \times g, 4{ }^{\circ} \mathrm{C}$ ) to collect the supernatant. Lipid peroxidation was calculated using the TBARS (thiobarbiturate reactive substances) assay. Quantification of TBARS corresponds to the MDA level that shows the extent of lipid peroxidation. Briefly, the assay mixture consisted of $1 \mathrm{~mL}$ above prepared supernatant, TCA $(20 \%, 1.5 \mathrm{~mL}), 1 \mathrm{~mL}$ of freshly prepared 
TBA $(0.67 \%)$ and absorbance was read at $535 \mathrm{~nm}$. Lipid peroxidation values were expressed as nmol TBARS $\mathrm{mg}^{-1}$ protein $(26,27)$.

For reduced glutathione (GSH) assay, the mixture consisted of 5,5'-dithio-bis-2-nitrobenzoic acid (DNTB) ( $0.4 \%$ in $1 \%$ sodium citrate) and double-distilled water. Absorbance was read at $412 \mathrm{~nm}$ against a blank. Values were expressed as micromoles of reduced glutathione per mg protein (26).

For reduced glutathione (GSH) assay, the mixture consisted of $0.3 \mathrm{~mL}$ supernatant, $2 \mathrm{~mL} \mathrm{Na}_{2} \mathrm{HPO}_{4}\left(0.3 \mathrm{~mol} \mathrm{~L}^{-1}\right), 0.25 \mathrm{~mL}$ of 5,5'-dithio-bis-2-nitrobenzoic acid (DNTB) (0.4\% in $1 \%$ sodium citrate) and double-distilled water. Absorbance was read at $412 \mathrm{~nm}$ against a blank. Values were expressed as micromoles of reduced glutathione per mg protein (26).

For catalase (CAT) assay, the reaction mixture consisted of $20 \mu \mathrm{L}$ supernatant, $1.2 \mathrm{~mL}$ of $\mathrm{H}_{2} \mathrm{O}_{2}\left(10 \mathrm{mmol} \mathrm{L}^{-1}\right)$ and $50 \mathrm{mmol} \mathrm{L}^{-1} \mathrm{PBS}(\mathrm{pH}$ 7.0). The decrease in absorbance was noted at $240 \mathrm{~nm}$ for $5 \mathrm{~min}$. One unit of CAT activity was defined as one micromole of $\mathrm{H}_{2} \mathrm{O}_{2}$ decomposed per minute at $25{ }^{\circ} \mathrm{C}$ using the molar absorption coefficient of $\mathrm{H}_{2} \mathrm{O}_{2}$ (43.6 $\mathrm{L} \mathrm{mol}^{-1} \mathrm{~cm}^{-1}$ at $\lambda_{\max }=240 \mathrm{~nm}$ ). The results were expressed as CAT U mg ${ }^{-1}$ protein (28).

To determine the superoxide dismutase (SOD) activity, a decrease of absorbance was measured using the microplate reader (and UV plates) at $340 \mathrm{~nm}$ in a reaction mixture

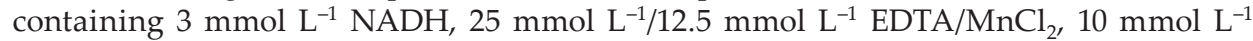
2-mercaptoethanol, and $50 \mathrm{~mL}$ of the cell lysate in $300 \mathrm{~mL}$ of triethanolamine-diethanolamine buffer (pH 7.4), after $20 \mathrm{~min}$. One SOD activity unit is defined as the amount of SOD capable of inhibiting $50 \%$ rate of NADH oxidation observed in the control. The results were expressed as SOD $\mathrm{U} \mathrm{mg}^{-1}$ protein (28).

\section{$T N F-\alpha$ and $N F \kappa B$}

Double antibody sandwich ELISA was used to determine the nuclear factor kappa-B $(\mathrm{NF \kappa B})$ and tumor necrosis factor (TNF- $\alpha$ ) levels. Standard methods provided in kits of TNF- $\alpha$ (Krishgen Biosystems, India) and NFkB (KinesisDx, USA) were followed. The sonicated culture sample was centrifuged at 2500 $\times \mathrm{g}$ for $20 \mathrm{~min}$ and the supernatant was used for the estimation of NFkB and TNF- $\alpha$ content. This supernatant was added to rat monoclonal antibody pre-coated wells (96 wells) and treated with secondary antibodies labeled with biotin followed by incubation for $1.5 \mathrm{~h}\left(37^{\circ} \mathrm{C}\right)$. Afterward, streptavidin-horseradish peroxidase was added to the wells and again incubated at $37^{\circ} \mathrm{C}$ for $1 \mathrm{~h}$ after covering the plate. After incubation, chromogenic solution A and B or TMB substrate was added that produced bluish color. A stop solution was added to stop the reaction and absorbance was noted at $450 \mathrm{~nm}\left(\lambda_{\max }\right)$ in ELISA microplate reader (iMARK, Bio-Rad, USA) within $15 \mathrm{~min}$ after the reaction has been stopped. The concentration of NFKB and TNF- $\alpha$ in an unknown sample was calculated from the standard curve. The amount of NFkB is expressed in ng $\mathrm{mL}^{-1}$ and TNF- $\alpha$ level in $\mathrm{pg} \mathrm{mL}^{-1}$.

\section{Statistical analysis}

All the data are expressed as mean \pm standard error of the mean (SEM). Statistical differences between the groups were assessed with a one-way ANOVA followed by Tukey's post-hoc test. A value of $p<0.05$ is considered statistically significant. 


\section{RESULTS AND DISCUSSION}

\section{Arbutin protects neurons against OGD triggered injury}

In pre-/post-condition paradigms, arbutin treatment in rat cortical culture without OGD (control arbutin) showed neuron viability akin to the control neurons that received DMSO vehicle only. Exposure to OGD (60 min) and reoxygenation $(24 \mathrm{~h})$ decreased the mean absorbance $\left(\lambda_{\max }=570 \mathrm{~nm}\right)$ for MTT that measures cell viability. MTT assay results indicated that the viability of cultured rat cortical neurons that were subjected to OGD/R was significantly decreased $(p<0.001)$ in comparison to vehicle-treated controls that were excluded from OGD/R treatment in pre- (Fig. 2a) and post-condition paradigms (Fig. 2b). The LDH activity was significantly $(p<0.001)$ enhanced when the cultured neurons were subjected to OGD/R in pre- (Fig. 2c) and post-condition experiments (Fig. 2d). These findings showed that OGD/R significantly compromised neuron integrity. Interruption of metabolic fuel and oxygen delivery hampers cellular oxidative metabolism and neuron survival. Restoration of oxygen supply further perpetuates the injury cascade in neurons (29). In this study, results of MTT assay revealed that arbutin $\left(100 \mu \mathrm{mol} \mathrm{L}^{-1}\right)$ pre-treatment $\left[\mathrm{F}_{(3,19)}=24.33 ; p<0.001\right]$ or post-treatment $\left[\mathrm{F}_{(3,19)}=27.85 ; p<0.001\right]$ significantly $(p<0.01)$ enhanced the viability of rat primary cortical neurons against OGD/R injury in comparison to neurons subjected to $\mathrm{OGD} / \mathrm{R}$ and vehicle treatments only. Furthermore, a significant decrease $(p<0.05)$ in the $\mathrm{LDH}$ activity in response to arbutin pre-treatment $\left[\mathrm{F}_{(3,19)}=16.67 ; p<0.001\right]$ and post-treat-
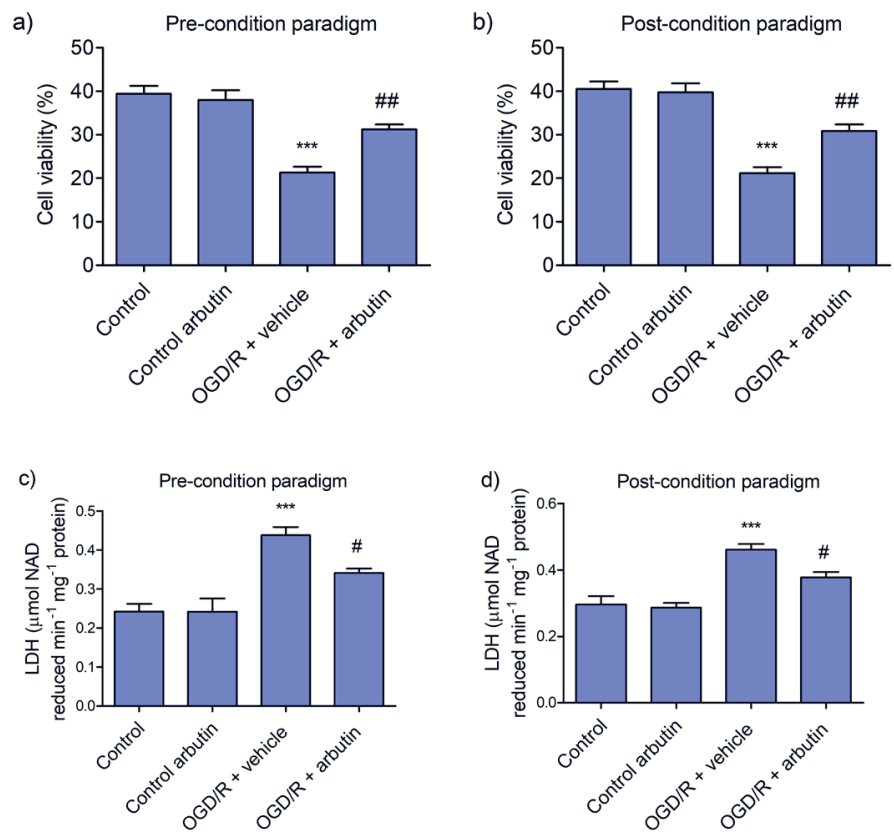

Fig. 2. Effects of arbutin on cell viability (MTT assay) and cell death (LDH assay) in rat primary neuron culture in: a) and c) pre- and b) and d) post-condition paradigms. Mean $\pm \operatorname{SEM}(n=5)$. Significant difference: ${ }^{* * *} p<0.001$ vs. control group, ${ }^{\#} p<0.05,{ }^{* \#} p<0.01$ vs. OGD/R+vehicle group. 

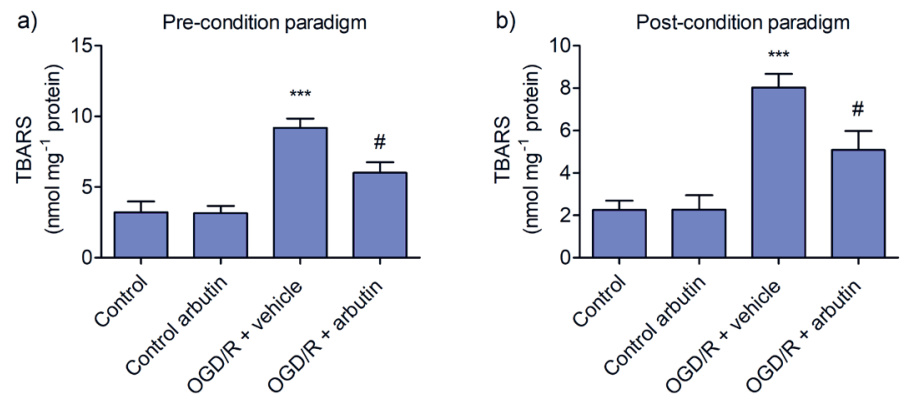

c)

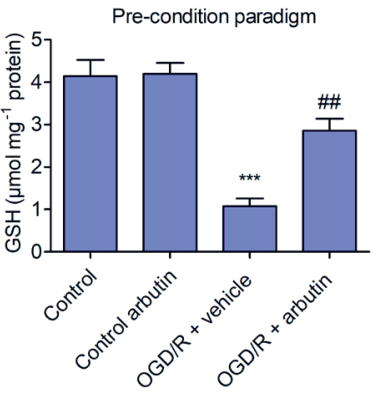

d)

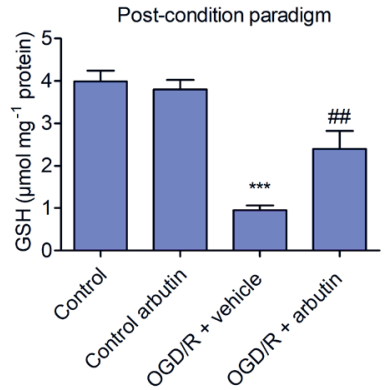

e)
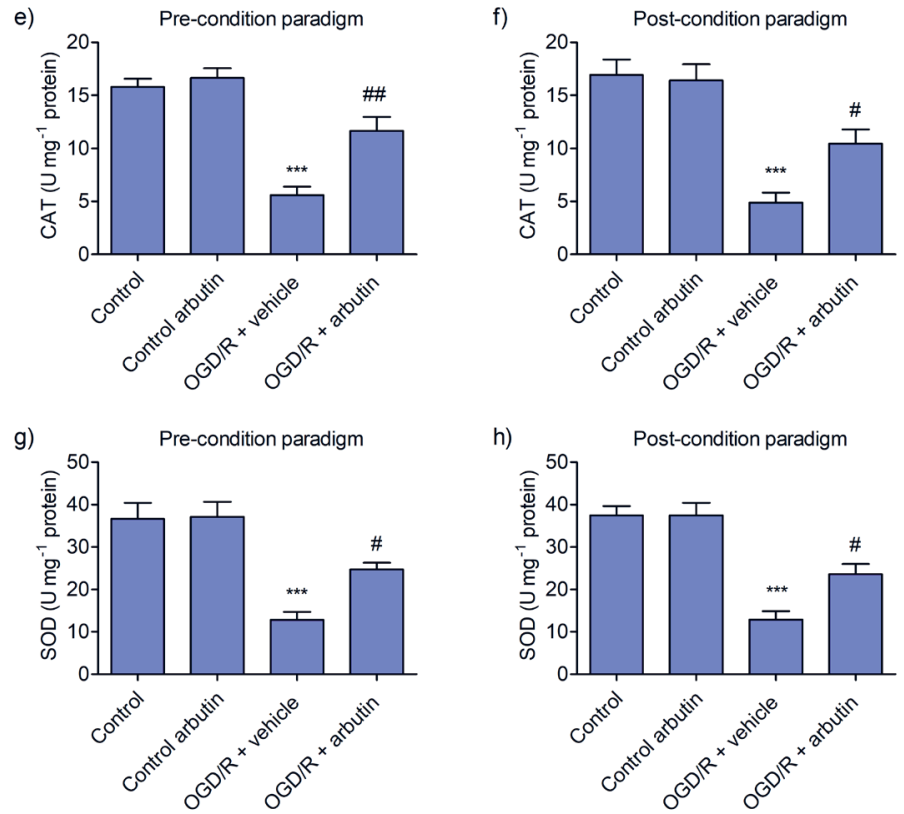

Fig. 3. Effects of arbutin on the parameters of oxidative stress in rat primary neuron culture in: a), c), e), and g) pre- and b), d) f) and h) post-condition paradigms. Mean $\pm \operatorname{SEM}(n=5)$. Significant difference: ${ }^{* * *} p<0.001$ vs. control group, ${ }^{*} p<0.05,{ }^{\# \#} p<0.01$ vs. OGD/R+vehicle group. 
ments $\left[\mathrm{F}_{(3,19)}=19.01 ; p<0.001\right]$ was observed in the cultured neurons subjected to OGD/R injury. In both, pre-/post-condition experiments, the LDH activity of arbutin treated neurons and vehicle-treated neurons were found to be similar.

\section{Arbutin reduces the oxidative stress in rat cortical neurons against OGD}

Vehicle (control) or arbutin (control arbutin) treated OGD deprived cultured neurons showed a similar TBARS content. In both, pre-/post-condition experiments, exposure to OGD markedly increased the lipid peroxidation (TBARS) in the rat cortical neurons as shown by a significant $(p<0.001)$ rise in TBARS content in comparison to the control neurons which received DMSO vehicle only. Hypoxia and lack of metabolic fuel (glucose) supply trigger ROS that causes aggregation of oxidized lipids. The extent of lipid peroxidation directly correlates with the severity of brain injury and inflammation (30). However, treatment of neurons with arbutin $\left(100 \mu \mathrm{mol} \mathrm{L}^{-1}\right)$ before $\left[\mathrm{F}_{(3,19)}=17.89 ; p<0.001\right]$ (Fig. 3a) or after $\left[\mathrm{F}_{(3,19)}=16.11 ; p<0.001\right]$ OGD (Fig. $\left.3 b\right)$ caused a significant $(p<0.05)$ decrease in the TBARS in comparison to the cultured neurons that were subjected to OGD and vehicle treatments only.

The endogenous antioxidants (e.g., GSH, catalase and SOD) maintain redox homeostasis within neurons by detoxifying several types of free radicals (e.g., ROS, $\mathrm{RNS}, \mathrm{H}_{2} \mathrm{O}_{2}$ ) and peroxidation products. In previous studies, a conspicuous decrease in sulfhydryl group

a)

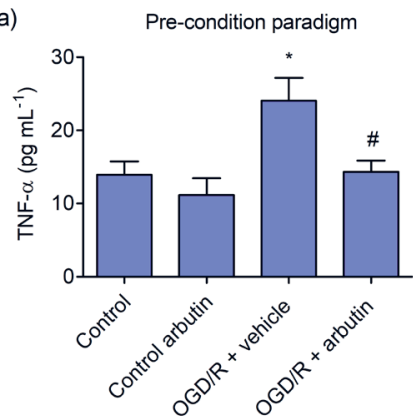

c)

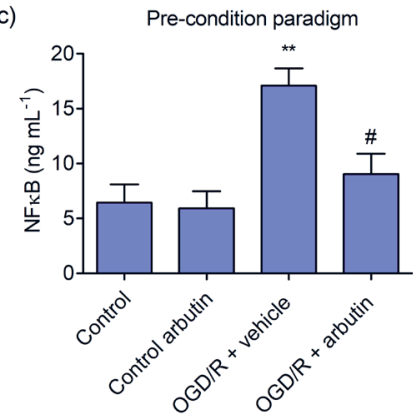

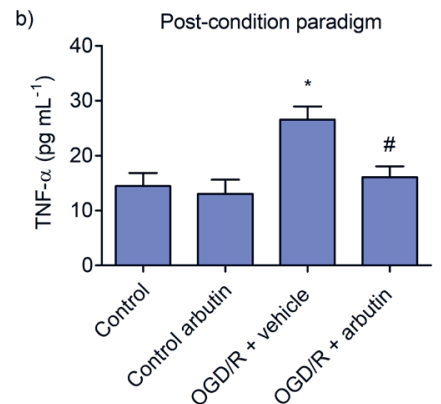

d)

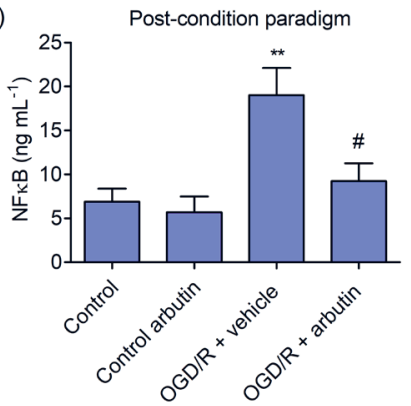

Fig. 4. Effects of arbutin on biomarkers of neuroinflammation (TNF- $\alpha$ and NFkB) in rat primary neuron culture in: a) and c) pre- and b) and d) post-condition paradigms. Mean \pm SEM $(n=5)$. Significant difference: ${ }^{*} p<0.05,{ }^{* *} p<0.01$ vs. control group, ${ }^{*} p<0.05$ vs. OGD/R+vehicle group. 
(-SH) antioxidants has been observed in cerebral ischemia (1, 31). Results of the present study revealed analogous antioxidant status (GSH, CAT and SOD) of neuron culture that received vehicle (control) or arbutin (control arbutin). Exposure of rat primary neuron culture to OGD/R caused a marked $(p<0.001)$ decrease in the GSH content, and CAT and SOD activities in comparison to vehicle treated control that were excluded from OGD/R treatment in pre- and post-condition paradigms. However, arbutin $\left(100 \mu \mathrm{mol} \mathrm{L}{ }^{-1}\right)$ treatment before OGD prevented the reduction of GSH $(p<0.01)\left[\mathrm{F}_{(3,19)}=26.13 ; p<0.001\right]$ (Fig. 3c), CAT $(p<0.01)\left[\mathrm{F}_{(3,19)}=27.25 ; p<0.001\right]$ (Fig. 3e) and SOD activity $(p<0.05)\left[\mathrm{F}_{(3,19)}=16.40 ; p<0.001\right]$ (Fig. $3 \mathrm{~g}$ ) in comparison to the neurons subjected to OGD and vehicle treatments only. Furthermore, post-ischemia arbutin treatment caused a significant rise in the GSH $(p<0.01)$ $\left[\mathrm{F}_{(3,19)}=26.06 ; p<0.001\right]$ (Fig. 3d), CAT $(p<0.05)\left[\mathrm{F}_{(3,19)}=18.12 ; p<0.001\right]$ (Fig. 3f) and SOD activity $(p<0.05)\left[\mathrm{F}_{(3,19)}=24.61 ; p<0.001\right]$ (Fig. 3h) in rat cortical neurons compared to neurons that received OGD and vehicle treatments.

\section{Arbutin decreases the inflammation in rat cortical neurons against OGD}

In vehicle- or arbutin-treated OGD deprived cultured neurons we observed a similar TNF- $\alpha$ and NFkB level. In agreement with previous reports $(1,7)$, the present findings showed that in pre-condition $\left[\mathrm{F}_{(3,19)}=6.166 ; p<0.001\right]$ (Fig. 4a) and post-condition experiments $\left[\mathrm{F}_{(3,19)}=6.863 ; p<0.001\right]$ (Fig. $4 \mathrm{~b}$ ), the rat cortical neurons subjected to OGD caused marked increase in the TNF- $\alpha(p<0.05)$ in comparison to the control neurons deprived of OGD. The NFkB level was also significantly enhanced $(p<0.01)$ in cultured neurons exposed to OGD in both pre-condition $\left[\mathrm{F}_{(3,19)}=9.575 ; p<0.001\right]$ (Fig. $4 \mathrm{c}$ ) and post-condition paradigms

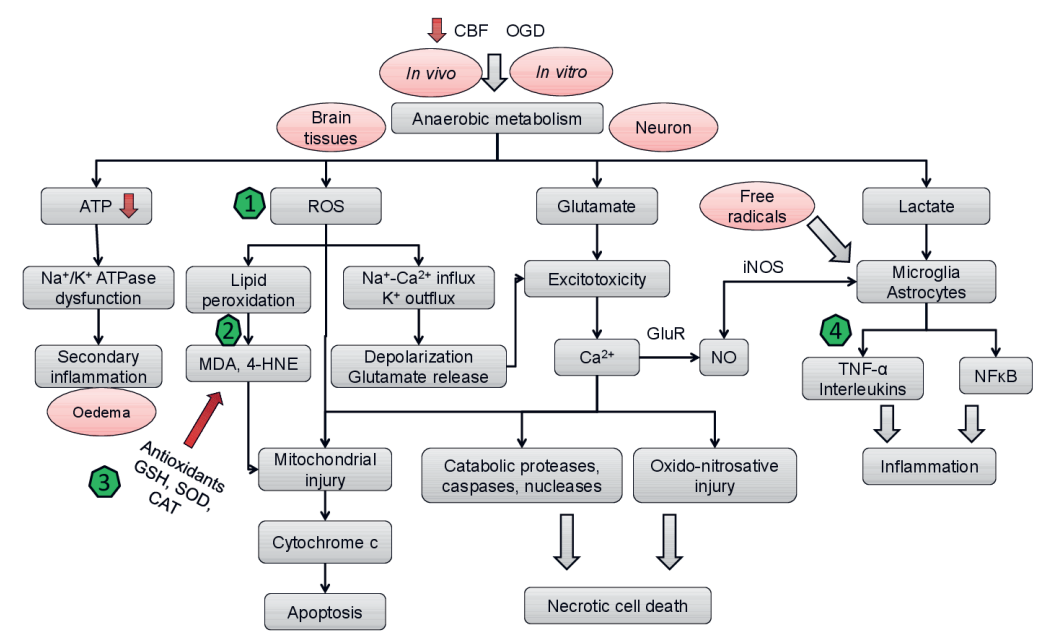

Fig. 5. Putative neuroprotective mechanism of arbutin against oxygen and glucose deprivation triggered ischemic injury to cultured neurons. 4-HNE - 4-hydroxy 2-nonenal, ATP - adenosine triphosphate, CAT - catalase, CBF - cerebral blood flow, GluR - glutamate receptors, GSH - glutathione, iNOS - inducible nitric oxide synthase, MDA - malondialdehyde, NF $\mathrm{B}$ - nuclear factor kappa-lightchain-enhancer of activated B cells, NO - nitric oxide, OGD - oxygen-glucose deprivation, ROS - reactive oxygen species, SOD - superoxide dismutase, TNF- $\alpha$ - tumour necrosis factor-alpha. 
$\left[\mathrm{F}_{(3,19)}=7.564 ; p<0.001\right]$ (Fig. $4 \mathrm{~d}$ ) when compared with the control neuron culture that were excluded from exposure to OGD. NFאB is a transcription factor that upregulates the expression of inflammatory cytokines (e.g., interleukins, inducible nitric oxide synthase, cyclo-

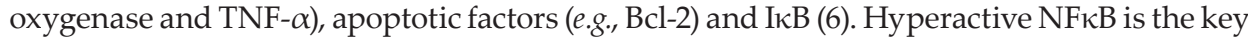
feature after post-ischemic reperfusion in the brain (31). However, treatment of neurons with arbutin before OGD prevented the increase in TNF- $\alpha(p<0.05)$ and NFkB $(p<0.05)$ in comparison with the vehicle-treated OGD/R neurons. Neuron culture treated with arbutin post OGD triggered ischemia showed a significant reduction in TNF- $\alpha(p<0.05)$ and NFkB $(p<0.05)$ as compared to the neuron culture that was subjected to OGD and vehicle treatments only. Results of the present study showed that treatment of cultured neurons with arbutin after or before OGD/R injury significantly attenuated the TNF- $\alpha$ and NFkB expressions. These findings amply indicate the anti-inflammatory activity of arbutin against OGD/R triggered ischemic injury in rat primary neuron culture (Fig. 5).

\section{CONCLUSIONS}

Exposure of primary neuron culture to OGD/R triggered oxidative stress and neuroinflammation while decreasing the neuron viability. Treatment with arbutin before or after OGD/R protected the neurons owing to control over oxidized lipids, inflammation, and an increase in antioxidants. The present findings indicate that arbutin can prevent the sequence of events that lead to ischemia. Furthermore, it can alleviate the progression of the neurodegenerative cascade after ischemic injury.

Acknowledgements. - The authors are thankful to the management of Swift School of Pharmacy (Rajpura) for providing the necessary research facilities.

Abbreviations, acronyms, symbols. - Bcl-2 - B-cell lymphoma 2, CAT - catalase, CBF - cerebral blood flow, ELISA - enzyme-linked immunosorbent assay, GluR - glutamate receptors, GSH - glutathione, 4-HNE - 4-hydroxy 2-nonenal, IкB - inhibitor kappa B, iNOS - inducible nitric oxide synthase, $\mathrm{LDH}$ - lactate dehydrogenase, NAD - nicotinamide adenine dinucleotide, NFкB - nuclear factor kappa-light-chain-enhancer of activated B cells, OGD - oxygen-glucose deprivation, PBS - phosphate buffer saline, $\mathrm{R}$ - reoxygenation, RNS - reactive nitrogen species, ROS - reactive oxygen species, SOD - superoxide dismutase, TBARS - thiobarbituric acid reactive substances, TNF- $\alpha$ - tumour necrosis factor- $\alpha$.

\section{REFERENCES}

1. Z. Yang, C. Weian, H. Susu and W. Hanmin, Protective effects of mangiferin on cerebral ischemiareperfusion injury and its mechanisms, Eur. J. Pharmacol. 771 (2015) 145-151; https://doi. org/10.1016/j.ejphar.2015.12.003

2. R. H. Lee, M. H. Lee, C. Y. Wu, A. Couto e Silva, H. E. Possoit, T. H. Hsieh, A. Minagar and H. W. Lin, Cerebral ischemia and neuroregeneration, Neural Regen. Res. 13 (2018) 373-385; https://doi. org/10.4103/1673-5374.228711

3. W. Li and S. Yang, Targeting oxidative stress for the treatment of ischemic stroke: Upstream and downstream therapeutic strategies, Brain Circ. 2 (2016) 153-163; https://doi.org/10.4103/23948108.195279

4. R. L. Jayaraj, S. Azimullah, R. Beiram, F. Y. Jalal and G. A. Rosenberg, Neuroinflammation: friend and foe for ischemic stroke, J. Neuroinflammation 16 (2019) Article ID 142 (24 pages); https://doi. org/10.1186/s12974-019-1516-2 
5. D. Lin, L. Wang, S. Yan, Q. Zhang, J. H. Zhang and A. Shao, The role of oxidative stress in common risk factors and mechanisms of cardio-cerebrovascular ischemia and depression, Oxid. Med. Cell. Longev. 2019 (2019) Article ID 2491927 (13 pages); https://doi.org/10.1155/2019/2491927

6. O. A. Harari and J. K. Liao, NF- $\kappa \mathrm{B}$ and innate immunity in ischemic stroke, Ann. N. Y. Acad. Sci. 1207 (2010) 32-40; https://doi.org/10.1111/j.1749-6632.2010.05735.x

7. M. Kawabori and M. A. Yenari, Inflammatory responses in brain ischemia, Curr. Med. Chem. 22 (2015) 1258-1277; https://doi.org/10.2174/0929867322666150209154036

8. T. Shichita, M. Ito and A. Yoshimura, Post-ischemic inflammation regulates neural damage and protection, Front. Cell. Neurosci. 8 (2014) Article ID 319 (8 pages); https://doi.org/10.3389/fncel.2014.00319

9. C. Pop, L. Vlase and M. Tamas, Natural resources containing arbutin. Determination of arbutin in the leaves of Bergenia crassifolia (L.) Fritsch. acclimated in Romania, Not. Bot. Hortic. Agrobot. Cluj-Napoca 37 (2009) 129-132; https://doi.org/10.15835/nbha3713108

10. F. Yousefi, S. Mahjoub, M. Pouramir and F. Khadir, Hypoglycemic activity of Pyrus biossieriana Buhse leaf extract and arbutin: Inhibitory effects on alpha amylase and alpha glucosidase, Casp. J. Int. Med. 4 (2013) 763-767.

11. F. Khadir, M. Pouramir, S. G. Joorsaraee, F. Feizi, H. Sorkhi and F. Yousefi, The effect of arbutin on lipid peroxidation and antioxidant capacity in the serum of cyclosporine-treated rats, Casp. J. Int. Med. 6 (2015) 196-200.

12. M. E. Shahaboddin, M. Pouramir, A. A. Moghadamnia, H. Parsian, M. Lakzaei and H.Mir, Pyrus biossieriana Buhse leaf extract: An antioxidant, antihyperglycaemic and antihyperlipidemic agent, Food Chem. 126 (2011) 1730-1733; https://doi.org/10.1016/j.foodchem.2010.12.069

13. B. E. Myagmar, E. Shinno, T. Ichiba and Y. Aniya, Antioxidant activity of medicinal herb Rhodococcum vitis-idaea on galactosamine-induced liver injury in rats, Phytomedicine 11 (2004) 416-423; https://doi.org/10.1016/j.phymed.2003.04.003

14. S. R. Ahmadian, M. Ghasemi-Kasman, M. Pouramir and F. Sadeghi, Arbutin attenuates cognitive impairment and inflammatory response in pentylenetetrazol-induced kindling model of epilepsy, Neuropharmacology 146 (2019) 117-127; https://doi.org/10.1016/j.neuropharm.2018.11.038

15. H. J. Lee and K. W. Kim, Anti-inflammatory effects of arbutin in lipopolysaccharide-stimulated BV2 microglial cells, Inflamm. Res. 61 (2012) 817-825; https://doi.org/10.1007/s00011-012-0474-2

16. M. Dadgar, M. Pouramir, Z. Dastan, M. Ghasemi-Kasman, M. Ashrafpour, A. A. Moghadamnia, S. Khafri and M. Pourghasem, Arbutin attenuates behavioral impairment and oxidative stress in an animal model of Parkinson's disease, Avicenna J. Phytomed. 8 (2018) 533-542.

17. Y. Ding, D. Kong, T. Zhou, N.-D. Yang, C. Xin, J. Xu, Q. Wang, H. Zhang, Q. Wu, X. Lu, K. Lim, B. Ma, C. Zhang, L. Li and W. Huang, $\alpha$-Arbutin protects against Parkinson's disease-associated mitochondrial dysfunction in vitro and in vivo, Neuromol. Med. 22 (2019) 56-67; https://doi. org/10.1007/s12017-019-08562-6

18. Z. Dastan, M. Pouramir, M. Ghasemi-Kasman, Z. Ghasemzadeh, M. Dadgar, M. Gol, M. Ashrafpour, M. Pourghasem, A. A. Moghadamnia and S. Khafri, Arbutin reduces cognitive deficit and oxidative stress in animal model of Alzheimer's disease, Int. J. Neurosci. 129 (2019) 1145-1153; https://doi.org/10.1080/00207454.2019.1638376

19. J. X. Wu, L. Y. Zhang, Y. L. Chen, S. S. Yu, Y. Zhao and J. Zhao, Curcumin pretreatment and posttreatment both improve the antioxidative ability of neurons with oxygen-glucose deprivation, Neural. Regen. Res. 10 (2015) 481-489; https://doi.org/10.4103/1673-5374.153700

20. J. Ye and Y. Zhang, Curcumin protects against intracellular amyloid toxicity in rat primary neurons, Int. J. Clin. Exp. Med. 5 (2012) 44-49.

21. L. Wang, L. Zhang, Z. B. Chen, J. Y. Wu, X. Zhang and Y. Xu, Icariin enhances neuronal survival after oxygen and glucose deprivation by increasing SIRT1, Eur. J. Pharmacol. 609 (2009) 40-44; https://doi.org/10.1016/j.ejphar.2009.03.033 
22. J. Xiang, Y. P. Tang, Z. Y. Zhou, P. Wu, Z. Wang, M. Mori and D. F. Cai, Apocynum venetum leaf extract protects rat cortical neurons from injury induced by oxygen and glucose deprivation in vitro, Can. J. Physiol. Pharmacol. 88 (2010) 907-917; https://doi.org/10.1139/y10-069

23. W. Zhao, S. Wang, T. Qin and W. Wang, Arbutin attenuates hydrogen peroxide-induced oxidative injury through regulation of microRNA-29a in retinal ganglion cells, Biomed. Pharmacother. 112 (2019) Article ID 108729; https://doi.org/10.1016/j.biopha.2019.108729

24. D. Gao, T. Huang, X. Jiang, S. Hu, L. Zhang and Z. Fei, Resveratrol protects primary cortical neuron cultures from transient oxygen-glucose deprivation by inhibiting MMP-9, Mol. Med. Rep. 9 (2014) 2197-2204; https://doi.org/10.3892/mmr.2014.2086

25. J. Wu, Q. Li, X. Wang, S. Yu, L. Li, X. Wu, Y. Chen, J. Zhao and Y. Zhao, Neuroprotection by curcumin in ischemic brain injury involves the Akt/Nrf2 pathway, PLoS ONE 8 (2013) e59843 (9 pages); https://doi.org/10.1371/journal.pone.0059843

26. R. AlJohri, M. AlOkail and S. H. Haq, Neuroprotective role of vitamin D in primary neuronal cortical culture, eNeurologicalSci 14 (2018) 43-48; https://doi.org/10.1016/j.ensci.2018.12.004

27. J. Chen-Roetling, L. Chen and R. F. Regan, Minocycline attenuates iron neurotoxicity in cortical cell cultures, Biochem. Biophys. Res. Commun. 386 (2009) 322-326; https://doi.org/10.1016/j. bbrc.2009.06.026

28. P. B. Godkar, R. K. Gordon, A. Ravindran and B. P. Doctor, Celastrus paniculatus seed oil and organic extracts attenuate hydrogen peroxide- and glutamate-induced injury in embryonic rat forebrain neuronal cells, Phytomedicine 13 (2006) 29-36; https://doi.org/10.1016/j.phymed.2003.11.011

29. M. G. Ryou and R. T. Mallet, An in vitro oxygen-glucose deprivation model for studying ischemiareperfusion injury of neuronal cells, Methods Mol. Biol. 1717 (2018) 229-235; https://doi. org/10.1007/978-1-4939-7526-6_18

30. T. S. Anthonymuthu, E. M. Kenny and H. Bayır, Therapies targeting lipid peroxidation in traumatic brain injury, Brain Res. 1640 (2016) 57-76; https://doi.org/10.1016/j.brainres.2016.02.006

31. A. Nurmi, P. J. Lindsberg, M. Koistinaho, W. Zhang, E. Juettler, M. L. Karjalainen-Lindsberg, F. Weih, N. Frank, M. Schwaninger and J. Koistinaho, Nuclear factor-kappaB contributes to infarction after permanent focal ischemia, Stroke 35 (2004) 987-991; https://doi.org/10.1161/01. STR.0000120732.45951.26 